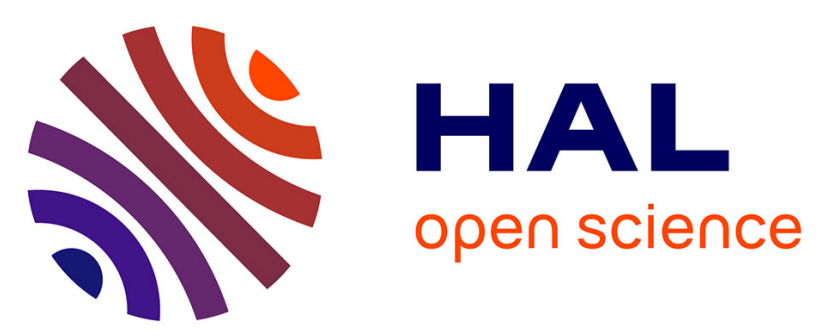

\title{
Feticide in second- and third-trimester termination of pregnancy for fetal anomalies: Results of a national survey
}

\author{
Paul Maurice, Alexandra Letourneau, Alexandra Benachi, Jean-marie
} Jouannic

\section{To cite this version:}

Paul Maurice, Alexandra Letourneau, Alexandra Benachi, Jean-marie Jouannic. Feticide in secondand third-trimester termination of pregnancy for fetal anomalies: Results of a national survey. Prenatal Diagnosis, 2019, 39 (13), pp.1269-1272. 10.1002/pd.5594 . hal-02966933

\section{HAL Id: hal-02966933 \\ https://hal.sorbonne-universite.fr/hal-02966933}

Submitted on 14 Oct 2020

HAL is a multi-disciplinary open access archive for the deposit and dissemination of scientific research documents, whether they are published or not. The documents may come from teaching and research institutions in France or abroad, or from public or private research centers.
L'archive ouverte pluridisciplinaire HAL, est destinée au dépôt et à la diffusion de documents scientifiques de niveau recherche, publiés ou non, émanant des établissements d'enseignement et de recherche français ou étrangers, des laboratoires publics ou privés. 
1 Feticide in second- and third-trimester termination of pregnancy for fetal

2 anomalies: results of a national survey

3 Running Head: Feticide in second and third trimester TOPFA

4 Word count: 2059

$5 \mathrm{Nb}$ of figure: 0

$6 \mathrm{Nb}$ of table: 2

7

8 Paul Maurice ${ }^{1}$, Alexandra Letrouneau ${ }^{2}$, Alexandra Benachi ${ }^{2}$, 3, Jean-Marie 9 Jouannic $^{1,3}$

$11{ }^{1}$ Fetal Medicine Departement, Trousseau Hospital, APHP.Sorbonne, Sorbonne 12 Université, 26 Avenue Arnorld Netter, 75012 Paris, France.

$13{ }^{2}$ Obstetrics and Gynaecology Department, Antoine Béclère Hospital, APHP, 14 University Paris 11, 157 Rue de la Porte de Trivaux, 92140 Clamart, France.

$15{ }^{3}$ Fédération Française des Centres Pluridisciplinaires de Diagnostic Prénatal, 91 16 Boulevard de Sébastopol, 75002 Paris, France.

18 Corresponding author: Jean-Marie Jouannic, Service de Médecine Foetale, Hôpital Armand Trousseau, 26 Avenue A. Netter, 75012 Paris, France.

20 Tel: +33144735228

21 Fax: +33144735222

22 Email: jean-marie.jouannic@aphp.fr 23

24 Conflict of interest: none

25 Funding: none 
Bulleted Statement:

27 What's already known about this topic?

Although the WHO recommends feticide for elective termination of pregnancy (TOP) after 20 weeks, in France, as in most other European countries, there is no legal obligation to perform this procedure in the framework of TOP for fetal anomalies. What does this study add?

First study on a national scale of feticide in the setting of termination of pregnancy for fetal anomalies showing that most TOP performed after 22 weeks in France are associated with feticide, usually after fetal anesthesia.

Data availability statement: The data that support the findings of this study are available from the corresponding author upon reasonable request.

Ethics Approval: N/A. This study consisted on evaluation of medical protocols. It does not involve any patients or personal staff data.

\section{Abstract}

Objective: to conduct an audit of the practice of feticide in second- and third-trimester termination of pregnancy for fetal anomalies (TOPFA) in prenatal diagnosis (PD) centers in France.

Results: A questionnaire was sent out to the 49 French PD centers and completed by 39/49 centers. 5350 TOPFA were performed. The gestational age after which feticide was performed was 20 weeks in 2 centers (5\%), 22 weeks in 28 centers (72\%), 23 weeks in 4 centers (10\%), and 24 weeks in 5 centers (13\%). Fifteen of 39 centers reported that feticide was not performed in all cases, because of a fetal abnormality 
associated with a high probability of rapid neonatal death (13 centers), pregnant woman's refusal (11 centers), and technical impossibility of performing feticide (1 center). Feticide was done using xylocaine in 38 of the 39 centers and using $\mathrm{KCl}$ in the remaining center. All but one of the centers before feticide used fetal anesthesia. Feticide was done on the day of induction of labor in 35/39 centers (90\%), after maternal epidural analgesia in 33 centers, or after maternal subcutaneous local anesthesia in 2 centers. Feticide was done the day before induction of labor in 2 centers.

Conclusion: In France, most TOPFA performed in second- and third trimester are associated with feticide, which is most often done after fetal anesthesia.

Acknowledgments: The authors would like to thank the members of the Board of the French Federation of Prenatal Diagnosis Centers (Dr P Vaast, Dr R Favre, Dr F Bretelle, Dr V Tsatstaris, Dr H Laurichesse), Miss L Chabert, Secretary of the French Federation of Prenatal Diagnosis Centers for their support and all the coordinators of the responding centers.

Keywords: termination of pregnancy for fetal anomalies, feticide, second- and third trimester, fetal analgesia.

Contribution: JMJ, PM, AL designed the study and interpreted the data. PM, JMJ, AB interpreted the data and wrote the article. 


\section{Introduction}

The growth of prenatal diagnosis over the last 3 decades has greatly increased the rate of prenatal detection of fetal anomalies. This rate varies among European countries, but ranges between 30 and $80 \%$ according to data from the European registers $^{1-3}$. Certain fetal anomalies can lead to the organization of specific perinatal management, sometimes with the possibility of specific fetal therapy ${ }^{4,5}$. In most European countries, termination of pregnancy for fetal anomalies (TOPFA) may be requested by the parents when the anomalies are severe, considered incurable, and associated with a high risk of severe disability. However, the legislative provisions, notably concerning a time limit beyond which TOPFA is no longer authorized, vary from one country to another.

French law authorizes TOPFA when there is a strong probability that the fetus has a particularly serious anomaly recognized as incurable at the time of diagnosis ${ }^{6}$. In France, there is no gestational age cut-off. When a pregnant woman opts for TOPFA, two fetal medicine specialists who are members of a prenatal diagnosis (PD) center must attest that the fetal anomaly is covered by the legal provisions in force.

Although the World Health Organization recommends feticide for elective termination of pregnancy after 20 weeks, in France, as in most other European countries, there is no legal obligation to perform this procedure in the framework of TOPFA. Several studies have examined the technical aspects of feticide, notably concerning the lethal substances used and their route of administration, ie, fetal or intra-amniotic injection ${ }^{7-11}$. Some studies have examined the psychological experiences of both the parents and the healthcare professionals involved ${ }^{12-14}$. Expert opinions have also been formulated concerning the ethical issues associated with whether or not feticide should be performed in the setting of TOP, whatever the 
97 indications. In contrast, no study to date has reported the incidence of feticide in the setting of TOPFA. Such an overview of the practice of feticide could serve as a basis for reflection by healthcare professionals and governmental decision-makers on standardization of practices and on the organization of TOPFA.

102 TOPFA during the second and third trimesters of pregnancy in (PD) centers in

103 France. The secondary objective was to study methods of feticide and why it may not 104 be performed.

\section{Material and methods}

The Fédération Française des Centres Pluridisciplinaires de Diagnostic Prénatal conducted a national questionnaire survey in 2018 concerning TOPFA performed in 2017. The questionnaire was drawn up by a committee appointed by

111 the Federation that comprised 8 center coordinators representative of physicians

112 involved in TOPFA, taking into account the gender and age of the physicians and the

113 number of TOPFA performed in their center, while ensuring a balanced geographical 114 distribution throughout France. This questionnaire, which was approved by means of 115 a consensus of all 8 coordinators, was limited to feticide in a setting of TOPFA, and 116 excluded termination of pregnancy for maternal reasons (life-threatening to pregnant 117 woman). The questions related notably to whether or not feticide was universally 118 performed, the gestational age at which feticide was practiced, the timing of feticide 119 in TOPFA, and the technical modalities of feticide: site of injection, use of prior fetal 120 anesthesia, type of lethal substance used. The questionnaire also included questions 121 on the existence of a protocol at the center, the medical resources available for 
122 ultrasound-guided termination of pregnancy, and the number of TOPFA done at the

123 centers during the previous year and reported to the Agence de la biomédecine, the

124 public body charged with oversight of the CPNs. Lastly, the questionnaire recorded

125 the reasons why some centers do not practice feticide universally. After the

126 questionnaire was sent out, two follow-ups were sent over a period of 6 months. A

127 member of the administrative staff of the Fédération Française des Centres

128 Pluridisciplinaires de Diagnostic Prénatal collected and anonymized the 129 questionnaire answers.

\section{Results}

Of 49 PD centers contacted, 39 completed the questionnaire (80\%). A total of 5350 TOPFA were done by these 39 centers in the year corresponding to the survey

134 (2017). According to data collected by the Agence de la biomédecine for this same year, a total of 6938 TOPFA were reported in France as a whole. Our survey

136 therefore covered $77 \%$ of the TOPFA performed. The median [range] number of 137 TOPFA performed in these centers was 121 [36-339]. The gestational age after 138 which feticide was performed was 20 weeks in 2 centers (5\%), 22 weeks in 28 139 centers (72\%), 23 weeks in 4 centers (10\%), and 24 weeks in 5 centers (13\%). In 140 each center, the median (extreme) number of experienced operators with ability to 141 perform feticide was $4(1-8)$. Of the 39 centers, $24(62 \%)$ reported systematic use of 142 feticide beyond the gestational age chosen by the center (Table 1). Fifteen of the 39 143 centers reported non-systematic use of feticide, the reason being a fetal anomaly 144 with a strong probability of rapid neonatal death (13 centers), refusal by the 145 pregnant woman (11 centers), and a technical impossibility of performing feticide (1 146 center). In all, 23 TOPFA were performed without feticide during the survey period, 
147 but this information was not provided by $17 / 39$ centers. The lethal substance used for

148 feticide was $1 \%$ or $2 \%$ xylocaine in $38 / 39$ centers and $\mathrm{KCl}$ in one center. All but one 149 centers used fetal anesthesia before feticide. The center that did not use fetal 150 anesthesia universally performed feticide by intracardiac injection of the lethal 151 substance. Fetal anesthesia was achieved by injection of fentanyl or pentothal or of a 152 mixture of the two, at a dose adapted to the ultrasound estimate of fetal weight. In 30 153 centers (82\%), fetal anesthesia was routinely achieved by ultrasound-guided injection 154 into the umbilical vein (Table 2). At the other centers, the injection site was 155 intracardiac or subcutaneous. Feticide was done on the day of induction of labor in $15635 / 39$ centers (90\%), after maternal epidural analgesia in 33 centers, and after 157 maternal subcutaneous anesthesia in 2 centers. Feticide was done the day before 158 the induction of labor, after local maternal anesthesia, in 2 centers (5\%). All CPNs reported that they worked in a network with maternity units outside 160 the tertiary institution of which they are a part, with the possibility of organizing 161 TOPFA in these maternity units. However, 19/39 centers (49\%) reported that TOPFA 162 were only performed in the maternity unit of the tertiary institution to which the CPN 163 was attached when the feticide was done, because the other maternity units did not 164 have staff with the technical skills required for this ultrasound-guided procedure 165 (Table 1). All but one of the CPNs that completed the questionnaire had the medical 166 resources required for emergencies $24 / 7$ in the case of unexpected labor when 167 TOPFA is scheduled with feticide.

\section{Discussion}


Ours is the first French study describing of the use of feticide in TOPFA. Its

172 results suggest that in France most TOPFA during the second and third trimesters of 173 pregnancy are practiced after fetal anesthesia and feticide. In most centers that 174 completed our questionnaire, feticide is almost always done after 22 weeks of 175 gestation, and very few TOPFA are organized without feticide after 22-24 weeks. While the World Health Organization recommends feticide for late TOP, in 177 France, unlike other countries, there is no legal obligation to perform feticide. Yet, 178 feticide appears to be ethically justified when it prevents neonatal demise associated with a risk of suffering or pain ${ }^{15-18}$. Studies in the literature on late TOP concern in large part second-trimester TOP, and notably TOP performed 181 according to the wishes of the parents, in the context of a normal pregnancy. These 182 TOP are authorized in several countries up until 24 weeks, as in the UK. Given that 183 almost all these TOP are performed using a surgical technique, the question of fetal 184 survival does not arise. The context of TOP for fetal anomalies is different because 185 TOP is legal after 22 weeks, notably in several European countries. In TOPFA, in 186 most cases, it may be helpful to perform a postmortem examination of the fetus to 187 define the fetal disease and to facilitate genetic counseling for subsequent 188 pregnancies. It is against this backdrop of induction of labor that feticide is posed. 189 However, there is the question of its acceptability to pregnant women and to 190 healthcare professionals. Most studies of feticide have focused on its technical 191 aspects: route of fetal injection, type of lethal substance used, and so forth ${ }^{7-10}$. These 192 studies mainly concentrated on maternal risks. It was thus shown that injection in the 193 umbilical vein involved the least risk to the pregnant woman ${ }^{7}$. It seems that 194 xylocaine is associated with the lowest maternal risk and achieves fetal asystole in 195 most cases ${ }^{8}$. Some authors consider that intracardiac injection is surer, and in some 
196 cases failure of injection in the umbilical cord has led to the birth of live infants ${ }^{11,19,20}$.

197 It is possible, moreover, that such failures are underreported in the literature. Even if exceptional, such failures expose the parents, and also the healthcare professionals delivering these neonates, to the risk of psychological trauma. To avoid such 200 situations, it seems prudent to recommend testing for fetal asystole using ultrasound, 201 at least 10-15 minutes after feticide by injection in the umbilical cord.

202 Although little discussed in the literature, feticide requires experience of 203 invasive, ultrasound-guided procedures. This may be a limiting factor in the 204 organization of some teams. In our study, 19/39 centers reported that TOPFA 205 requiring feticide was performed in the maternity unit of the PD center because other 206 maternity units in the region had no physician able to perform the procedure. 207 Interestingly, the intra-amniotic injection of digoxin in TOP has been reported to 208 achieve fetal demise within about 24 hours ${ }^{10}$. This injection is technically simpler than 209 injection in the umbilical cord or intracardiac injection. In a recent study, this 210 technique achieved fetal demise in up to $93 \%$ of reported cases ${ }^{10}$. The risk of failure 211 seemed to be greater in the case of maternal obesity. The results of this study are 212 interesting as they could argue in favor of easier access to this procedure, notably for 213 couples living far from tertiary centers. However, the precise time lapse between 214 intra-amniotic injection and fetal death is unknown. Our study shows that most 215 French CPNs perform fetal anesthesia before feticide in accordance with the 216 guidelines of the French College of Obstetricians and Gynecologists ${ }^{21}$. Interestingly, 217 fetal pain is little considered in studies on late TOP.

218 The strength of our study is that fetal medicine in France is organized in 219 approved specialized centers, which were set up following the bioethics laws of 1994. 220 At the time of our study, there were 49 such centers throughout mainland France and 
221 French overseas territories. The expert members of these centers are accredited by

222 the Agence de la biomédecine, the public body that has oversight of the running and 223 organization of these 49 centers. This facilitates centralization of the organization of

224 TOPFA. French legislation imposes no limit on the term of gestation for TOPFA when 225 there is a strong probability that the unborn child has a serious disease 226 acknowledged to be incurable, at the time of diagnosis. Even though legal provisions 227 differ from one country to another, late TOPFA is authorized in several countries, 228 notably in Europe.

229 The main limitation of our study is that not all the PD centers contacted 230 completed our questionnaire. Those that did, however, accounted for $77 \%$ of TOPFA. 231 In addition, our figures are in line with the proportion of feticides reported in the 232 EPIPAGE cohort, which studied TOP prevalence and indications in 7804 premature 233 births (between 22 weeks and 31 weeks plus 6 days) ${ }^{22}$. In this study, for TOPFA, the 234 rate of feticide was $80 \%$ at 24 weeks of gestation and over $90 \%$ from 26 weeks. 235 Moreover, among the $11 / 49$ centers that failed to respond in our study, there was no 236 regional or workload disparity that could have introduced bias. Another limitation of 237 our survey is that it was self-report in nature, which could be a source of bias. 238 However, most of the information corresponds to data that must be reported every 239 year to the Agence Nationale de la Biomédécine, which regularly conducts quality 240 controls of transmitted data.

Ours is the first study on a national scale of feticide in the setting of TOPFA. It 243 shows that most TOPFA performed most TOPFA performed in second- and third 244 trimester are associated with feticide, usually after fetal anesthesia administered by 245 injection in the umbilical cord. 


\section{References}

1. Garne $E$, Loane $M$, Dolk $H$, et al. Prenatal diagnosis of severe structural congenital malformations in Europe. Ultrasound Obstet Gynecol Off J Int Soc Ultrasound Obstet Gynecol. 2005 Jan;25(1):6-11.

2. Ferrier $\mathrm{C}$, Dhombres $\mathrm{F}$, Khoshnood $\mathrm{B}$, et al. Trends in resource use and effectiveness of ultrasound detection of fetal structural anomalies in France: a multiple registry-based study. BMJ Open. 2019 Feb 15;9(2):e025482.

3. Braz P, Machado A, Matias Dias C. The impact of prenatal diagnosis on congenital anomaly outcomes: Data from 1997 to 2016. Eur J Med Genet. 2018 Sep;61(9):508-12.

4. Adzick NS, Thom EA, Spong $\mathrm{CY}$, et al. A randomized trial of prenatal versus postnatal repair of myelomeningocele. N Engl J Med. 2011 Mar 17;364(11):9931004.

5. Zwiers C, Oepkes D, Lopriore E, et al. The near disappearance of fetal hydrops in relation to current state-of-the-art management of red cell alloimmunization. Prenat Diagn. 2018;38(12):943-50.

6. Code de la santé publique - Article L2213-1. Code de la santé publique 09, 2011.

7. Senat MV, Fischer C, Ville Y. Funipuncture for fetocide in late termination of pregnancy. Prenat Diagn. 2002 May;22(5):354-6.

8. Senat MV, Fischer C, Bernard JP, Ville Y. The use of lidocaine for fetocide in late termination of pregnancy. BJOG Int J Obstet Gynaecol. 2003 Mar;110(3):296300 .

9. Evans MI, Goldberg JD, Dommergues et al. Efficacy of second-trimester selective termination for fetal abnormalities: international collaborative experience among the world's largest centers. Am J Obstet Gynecol. 1994 Jul;171(1):90-4.

10. Sharvit M, Klein Z, Silber M, et al. Intra-amniotic digoxin for feticide between 21 and 30 weeks of gestation: a prospective study. BJOG Int J Obstet Gynaecol. 2019 Jun;126(7):885-9.

11. Pasquini L, Pontello V, Kumar S. Intracardiac injection of potassium chloride as method for feticide: experience from a single UK tertiary centre. BJOG Int J Obstet Gynaecol. 2008 Mar;115(4):528-31. 
12. Garel M, Etienne E, Blondel B, Dommergues M. French midwives' practice of termination of pregnancy for fetal abnormality. At what psychological and ethical cost? Prenat Diagn. 2007 Jul;27(7):622-8.

13. Dommergues M, Cahen F, Garel M, et al. Feticide during second- and thirdtrimester termination of pregnancy: opinions of health care professionals. Fetal Diagn Ther. 2003 Apr;18(2):91-7.

14. Alsulaiman A, Hewison J, Abu-Amero KK, et al. Attitudes to prenatal diagnosis and termination of pregnancy for 30 conditions among women in Saudi Arabia and the UK. Prenat Diagn. 2012 Nov;32(11):1109-13.

15. Spielman B. Certainty and agnosticism about lethal injection in late abortion. J Clin Ethics. 1995;6(3):270-2.

16. Callahan JC. Ensuring a stillborn: the ethics of fetal lethal injection in late abortion. J Clin Ethics. 1995;6(3):254-63.

17. Isada NB, Pryde PG, Johnson MP et al. Fetal intracardiaque potassium chloride injection to avoid the hopeless resuscitation of an abormal abortus: I. Clinical issues. Obstet Gynecol 1992;80:296-9.

18. Fletcher JC, Isada NB, Pryde PG et al. Fetal intracardiaque potassium chloride injection to avoid the hopeless resuscitation of an abormal abortus: II. Ethical issues. Obstet Gynecol 1992;80:310-3.

19. Gill P, Cyr D, Afrakhtah M, et al. Induction of fetal demise in advanced pregnancy terminations: report on a funic potassium chloride protocol. Fetal Diagn Ther. 1994 Aug;9(4):278-82.

20. Bhide A, Sairam S, Hollis B, Thilaganathan B. Comparison of feticide carried out by cordocentesis versus cardiac puncture. Ultrasound Obstet Gynecol Off $\mathrm{J}$ Int Soc Ultrasound Obstet Gynecol. 2002 Sep;20(3):230-2.

21. Collège National des Gynécologues et Obstétriciens Français. Interruption médical de grossesse. Processus décisionnel et prise en charge 2008.

http://www.cngof.asso.fr/d livres/2008 GO 041 houfflin.pdf

22. Monier I, Lelong N, Ancel P-Y, et al. Indications leading to termination of pregnancy between 22+0 and 31+6 weeks of gestational age in France: A population-based cohort study. Eur J Obstet Gynecol Reprod Biol. 2019 Feb;233:12-8. 
Table 1: Organization of feticide during second- and third-trimester termination of pregnancies among the 39 prenatal diagnosis centers

\begin{tabular}{lc}
\hline & Yes \\
\hline Is feticide done universally? & $24 / 39$
\end{tabular}

Does your center's organization allow "emergency" feticide 24/7 (eg, in the case of spontaneous labor)?

In the maternity unit housing your CPD

In another maternity unit of the network of your CPD

Does the indication for feticide in TOP imply management of the patient outside her original maternity unit? 
Table 2: Site of injection of the fetal anesthesia and lethal substance among the 39 prenatal diagnosis centers

\begin{tabular}{lcccc}
\hline & $\begin{array}{c}\text { Umbilical } \\
\text { cord }\end{array}$ & Intracardiac & Subcutaneous & $\begin{array}{c}\text { Depending on } \\
\text { the conditions }\end{array}$ \\
\hline $\begin{array}{l}\text { Site of injection of the } \\
\text { fetal anesthesia }\end{array}$ & $31 / 38$ & $2 / 38$ & $0 / 38$ & $3 / 38$ \\
$\begin{array}{l}\text { Site of injection of the } \\
\text { lethal substance }\end{array}$ & $9 / 39$ & $3 / 39$ & N/A & $27 / 39$ \\
\hline
\end{tabular}

